\title{
Chemically Induced Virus Resistance in Arabidopsis thaliana Is Independent of Pathogenesis-Related Protein Expression and the NPR1 Gene
}

\author{
Chui Eng Wong, Rachael A. J. Carson, and John P. Carr \\ Department of Plant Sciences, University of Cambridge, Downing Street, Cambridge CB2 3EA U.K. \\ Submitted 21 June 2001. Accepted 1 October 2001.
}

Salicylic acid (SA) treatment triggers inhibition of replication or movement of several positive-sense RNA plant viruses in tobacco. This resistance can also be stimulated by nonlethal concentrations of cyanide and antimycin A (AA) without triggering induction of pathogenesis-related PR-1 protein genes. In two ecotypes of Arabidopsis thaliana (Columbia and Nössen), SA-induced resistance to a tobamovirus, Turnip vein clearing virus (TVCV), was also induced by nonlethal concentrations of cyanide and AA without concomitant induction of $P R-1$ gene expression. Furthermore, chemically induced resistance to TVCV, as well as the induction of the plant mitochondrial alternative oxidase (a potential target for the chemicals), was independent of NPR1, a gene that plays a key role downstream of $\mathrm{SA}$ in the induction of $\mathrm{PR}$ proteins. The chemically induced resistance to TVCV appeared to be due to inhibition of replication at the site of inoculation. Taken together, these results show that in Arabidopsis, as in tobacco, resistance to viruses can be induced via a distinct branch of the defensive signal transduction pathway. This suggests that the existence of this virus-specific branch may be widespread among plants.

Salicylic acid (SA) is one of the key chemical signals produced in response to pathogen attack on resistant plants and is required for the induction of systemic acquired resistance (SAR) (Dempsey et al. 1999). Production of SA and induction of SAR are most often exhibited following a hypersensitive response (HR), i.e., rapid, localized cell death occurring at the point of pathogen entry (Heath 2000). Activation of the HR is governed by resistance genes encoding receptors that identify specific pathogens (Baker et al. 1997; Staskawicz et al. 1995). The subsequent induction of SAR appears to be governed by a complex signal transduction process (Genoud and Métraux 1999; Moller and Chua 1999).

Plants exhibiting SAR are able to better defend themselves against a remarkably broad range of pathogens, but the exact mechanisms that are used to restrict pathogen spread are not fully understood (Hammerschmidt 1999). However, work using several host-pathogen combinations has shown that cell death alone is insufficient to restrict pathogen spread (Cole et al. 2001; Kim and Palukaitis 1997; Mittler et al. 1996; Wright

Corresponding author: John P. Carr; Fax: +44-1223-333953; E-mail: jpc1005@hermes.cam.ac.uk et al. 2000; Yu et al. 1999). Thus, treatment of plants with solutions of SA can enhance resistance to viruses, bacteria, and fungi, even in susceptible plants that do not possess resistance genes and would otherwise be completely susceptible to these pathogens (Chivasa et al. 1997; White et al. 1983).

SA induces a number of defense-related genes, including some of those that encode pathogenesis-related (PR) proteins. The PR proteins comprise families of highly diverse sets of antimicrobial or potentially antimicrobial agents produced in response to stress or pathogen attack (van Loon and van Strien 1999). Some of the SA-inducible PR proteins have known antibacterial or antifungal properties, and this may explain, at least in part, how SA induces resistance to bacterial or fungal plant pathogens (Bowles 1990; Hammerschmidt 1999). Unfortunately, none of the PR proteins examined so far have been shown to have antiviral activity (Cutt et al. 1989; Linthorst et al. 1989).

Work published to date suggests that SA can inhibit at least two points in the virus infection cycle, replication (Chivasa et al. 1997; Hooft Van Huijsduijnen et al. 1986) and systemic movement (Naylor et al. 1998). In tobacco leaf tissue inoculated with Tobacco mosaic virus (TMV) (Chivasa et al. 1997) or Potato virus X (PVX) (Naylor et al. 1998), SA inhibited the accumulation of viral RNAs. However, in the same host, SA had little effect on the replication or gene expression of another positive-sense, single-stranded RNA virus, Cucumber mosaic virus (CMV), although it did inhibit systemic movement of the virus (Naylor et al. 1998). Thus, SA triggers at least two apparently distinct antiviral mechanisms (Murphy et al. 1999, 2001).

In tobacco, both of the SA-induced resistance mechanisms were antagonized by salicylhydroxamic acid (SHAM) (Chivasa et al. 1997; Naylor et al. 1998). However, SHAM did not antagonize SA-induced resistance to a bacterial or a fungal pathogen (Chivasa et al. 1997). Additionally, it was found that nontoxic concentrations of cyanide and antimycin A (AA) induced resistance to TMV without any concomitant induction of the gene or genes encoding the PR-1 family of PR proteins (Chivasa and Carr, 1998). Taken together, these data indicate that the defensive signal transduction pathway separates downstream of SA into two branches, one leading to the induction of PR-1 proteins and the induction of antibacterial and antifungal resistance, while the other leads to the induction of resistance to viral pathogens (Murphy et al. 1999).

Since SA, cyanide, and AA are inducers of the alternative oxidase (Aox) gene and SHAM is an inhibitor of AOX activity, the suggestion has been made that, in tobacco, AOX may be 
involved in the induction of resistance to viruses (Murphy et al. 1999). AOX is the terminal oxidase of 'alternative respiration,' a process that can occur in the mitochondria of plants (and certain fungi) (Affourtit et al. 2001; Day et al. 1995; Wagner and Moore 1997). Alternative respiration has long been known to function in heat production (thermogenesis) in specialized plants (Day et al. 1995; Wagner and Moore 1997) and has recently been shown to play a role in defense against reactive oxygen species (Maxwell et al. 1999). So far, however, evidence for its role in defense against viruses is indirect or circumstantial (Murphy et al. 1999, 2001).

Recently, the existence of a virus-specific signaling pathway in Arabidopsis was reported by Kachroo and associates (2000). They showed that resistance to Turnip crinkle virus (TCV) in Arabidopsis plants carrying the $H R T$ resistance gene specifying resistance to TCV (Dempsey et al. 1993, 1997) is dependent on SA but is independent of the NPRI gene (also called NIMI) (Cao et al. 1997; Ryals et al. 1997). The significance of this result is that NPR1, a protein that plays a key role downstream of SA in regulating the induction of $P R$ gene transcription, is not required for virus resistance (Després et al. 2000; Zhou et al. 2000).

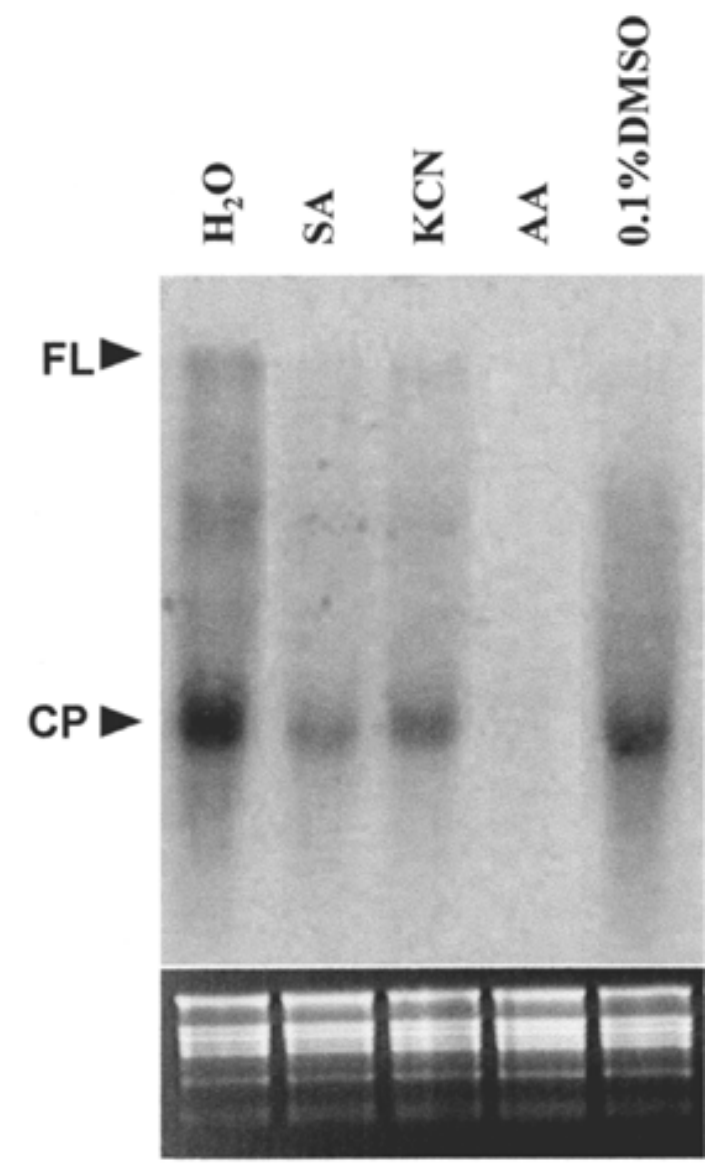

Fig. 1. Accumulation of Turnip vein clearing virus (TVCV) RNA in chemically treated Arabidopsis leaf tissue. Detached leaves (10 per sample) were floated for 2 days on water (Control), $0.5 \mathrm{mM}$ salicylic acid (SA), $50 \mu \mathrm{M}$ potassium cyanide (KCN), or $50 \mu \mathrm{M}$ antimycin A (AA) dissolved in dimethylsulfoxide (DMSO) or were floated on $0.1 \%$ DMSO (Control) prior to inoculation with TVCV $(10 \mu \mathrm{g} / \mathrm{ml})$. Leaves were returned to the replenished chemical solutions for 5 more days and RNA was extracted from each group of leaves. Equal amounts $(10 \mu \mathrm{g})$ of RNA from each sample were analyzed by northern blotting using a ${ }^{32} \mathrm{P}$-labeled Tobacco mosaic virus (TMV) coat protein cDNA as the hybridization probe. The ethidium bromide-staining pattern for the same gel is shown in the bottom row to demonstrate equal loading of RNA. FL = position of full-length (genomic) viral RNA, and $\mathrm{CP}=$ position of viral coat protein subgenomic mRNA.
The results of Kachroo and associates (2000) are consistent with our hypothesis that resistance to viruses is dependent on a separate branch of the defensive signal transduction pathway (Murphy et al. 1999, 2001). However, Kachroo and associates (2000) did not examine chemically induced resistance to viruses. In this study, we set out to determine if resistance to viruses could be induced by AA or cyanide in Arabidopsis and whether or not this resistance was independent of the NPRl gene. The virus chosen for this study, Turnip vein clearing virus (TVCV), has been used previously to investigate virus infection in Arabidopsis (Lartey et al. 1998). TVCV was selected for this study, rather than TCV, because it is a tobamovirus that is closely related to TMV, the virus used most extensively in previous studies of SA-induced resistance to viruses in tobacco.

We found in wild-type Arabidopsis that SA, AA, and cyanide could induce resistance to TVCV. Furthermore, induction of resistance to TVCV by AA and cyanide was independent of the induction of $P R-1$ proteins. We also found that SA- and AA-induced resistance to TVCV could occur in plants carrying the nprl mutation or the allelic mutant, sail (Shah et al. 1997). These results complement the work of Kachroo and associates (2000) and show that the virus-specific branch of the SAdependent defensive signal transduction pathway occurs in Arabidopsis and is not unique to tobacco.

\section{RESULTS}

Chemically induced resistance to TVCV in Arabidopsis.

Leaves of 4- to 5-week-old Arabidopsis plants were detached and floated on water or chemical solutions for 2 days prior to mock inoculation or inoculation with TVCV. At 5 days post inoculation, total RNA or total soluble protein was extracted from the leaves. Detection of TVCV RNA was carried out by northern blot analysis using a ${ }^{32} \mathrm{P}$-labeled cDNA fragment encoding the TMV coat protein $(\mathrm{CP})$. This cross-hybridizes strongly to the $\mathrm{CP}$ gene sequence of TVCV. Analysis of protein was carried out by sodium dodecyl sulfate-polyacrylamide gel electophoresis (SDS-PAGE) and immunoblotting using an antiserum against the $\mathrm{CP}$ of TMV, since this antiserum cross-reacts strongly with the CP of TVCV.

We consistently found that less TVCV RNA (Fig. 1) or TVCV CP (Fig. 2) accumulated in virus-inoculated Arabidopsis leaves floated on solutions of $0.5 \mathrm{mM} \mathrm{SA}, 50 \mu \mathrm{M}$ AA, or 50 $\mu \mathrm{M}$ potassium cyanide $(\mathrm{KCN})$ than in control leaves that had been floated on water or $0.1 \%$ dimethylsulfoxide (DMSO). These experiments investigating viral RNA and CP accumulation were carried out two and four times. The results with chemically treated, floated leaves show that all of the chemi-

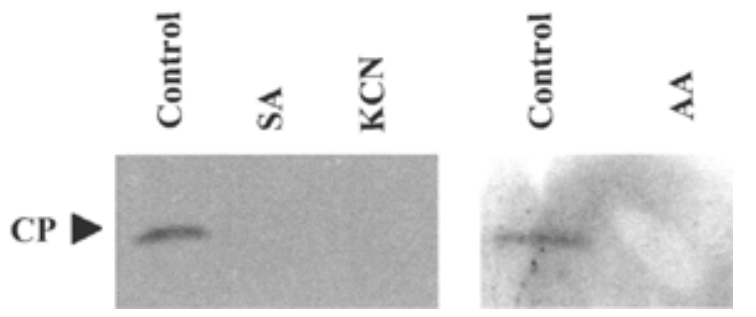

Fig. 2. Accumulation of Turnip vein clearing virus (TVCV) coat protein (CP) in chemically treated Arabidopsis tissue. Detached leaves (10 per sample) were floated for 2 days on water (Control), $0.5 \mathrm{mM}$ salicylic acid (SA), $50 \mu \mathrm{M}$ potassium cyanide $(\mathrm{KCN})$, or $50 \mu \mathrm{M}$ antimycin A (AA) dissolved in dimethylsulfoxide (DMSO) or were floated on $0.1 \%$ DMSO (Control) prior to inoculation with TVCV $(10 \mu \mathrm{g} / \mathrm{ml})$. Leaves were returned to the replenished chemical solutions for 3 more days before protein extraction. Each gel lane represents a total of $30 \mu \mathrm{g}$ of proteins from each sample. The proteins were analyzed by western blotting using a polyclonal rabbit anti-Tobacco mosaic virus $\mathrm{CP}$ serum to detect TVCV CP. 
cals induced resistance to TVCV in directly inoculated tissues. This suggests that the nature of the resistance is an inhibition of TVCV replication or cell-to-cell movement, or both. This is similar to the resistance induced by these chemicals against the related virus, TMV, in tobacco (Carr and Chivasa 1998).

We felt it was necessary to verify that the treatment with $\mathrm{KCN}$ or AA solutions was not responsible for the decrease in TVCV accumulation simply by poisoning Arabidopsis tissue. Detached leaves that had been floated on water, on $50 \mu \mathrm{M}$ $\mathrm{KCN}$, or on $50 \mu \mathrm{M}$ AA for 3 days were fed with a solution of ${ }^{35} \mathrm{~S}$-labeled methionine. SDS-PAGE analysis of ${ }^{35} \mathrm{~S}$-labeled proteins extracted from the leaf samples showed that there were no major qualitative differences between the polypeptides (approximately 14 to $100 \mathrm{kDa}$ ) synthesized in the control or the $\mathrm{KCN}$ - or AA-treated tissues (Fig. 3). Scintillation counting of trichloroacetic acid-insoluble material indicated that there were no significant quantitative differences between the two treatments in terms of incorporation of the radiolabel into protein (data not shown). These experiments were carried out twice and yielded similar results in each case. As seen previously in tobacco (Chivasa and Carr 1998), KCN and AA do not seem to exert a nonspecific effect on virus accumulation by causing a gross decrease in overall protein synthesis.

In tobacco, the induction of resistance to viruses by either SA (Chivasa et al. 1997; Naylor et al. 1998) or cyanide (Chivasa and Carr 1998) could be inhibited by SHAM. However, we found that, in Arabidopsis, SHAM antagonized the induction of resistance by cyanide or SA in only two out of the four experiments carried out (data not shown). Thus, SHAM does not appear to be a reliable inhibitor of SA or cyanide-induced resistance to viruses in Arabidopsis.

\section{Chemical induction of transcripts encoding Arabidopsis PR-1 and AOX proteins.}

$P R-1$ gene expression is typically used as a marker for the induction of SA-induced resistance. However, in a previous study in tobacco, we found that $P R-1$ gene expression was not activated by KCN or AA, even though these chemicals induced resistance to TMV (Chivasa and Carr 1998). Our results indicate that in Arabidopsis, as in tobacco, KCN and AA do not induce $P R-1$ gene expression. Using northern blot analysis, we examined the steady state levels of $P R-1$ transcripts in Arabi-
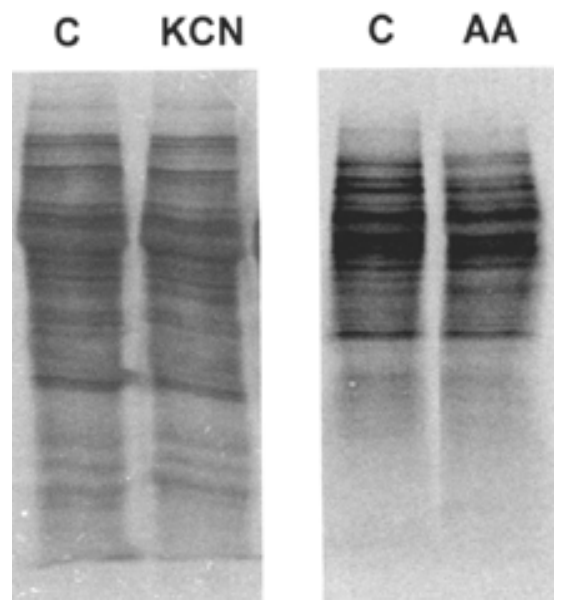

Fig. 3. The effects of potassium cyanide $(\mathrm{KCN})$ and antimycin $\mathrm{A}(\mathrm{AA})$ on protein synthesis in Arabidopsis leaf tissue. Arabidopsis leaves were floated on water (Control: C), $50 \mu \mathrm{M} \mathrm{KCN}$, or $50 \mu \mathrm{M}$ (AA) for 3 days and were then incubated on a solution of $\mathrm{L}-\left[{ }^{35} \mathrm{~S}\right]$ methionine for $4 \mathrm{~h}$. Soluble proteins were extracted from the leaves and analyzed by sodium dodecyl sulfate-polyacrylamide gel electophoresis and autoradiography. Equal amounts of protein (Bradford 1976) were loaded on each lane of the gel. dopsis plant tissue that had been treated with $\mathrm{SA}, \mathrm{AA}$, or $\mathrm{KCN}$. As expected, steady state levels of $P R-1$ RNA were increased in SA-treated tissue (Fig. 4). However, no such increase was observed in tissues treated with resistance-inducing concentrations of $\mathrm{KCN}$ or AA (Fig. 4). This experiment was carried out three times and yielded the same result in each case (data not shown).

Aox gene expression increases in tobacco (Chivasa and Carr 1998; Lennon et al. 1997) and Arabidopsis (Lacomme and Roby 1999; Simons et al. 1999) tissue undergoing pathogen-induced HR and has been correlated with SA-induced virus-specific resistance in tobacco (Murphy et al. 1999, 2001). Arabidopsis has at least four Aox genes, one of which, Aox 1a, is inducible by AA treatment (Saisho et al. 1997). We used Aox laspecific primers to detect Aox $1 a$ transcripts in total leaf RNA by reverse-transcription polymerase chain reaction (RT-PCR). Steady-state transcripts for Aox $1 a$ increased significantly in plants sprayed with resistance-inducing concentrations of SA, $\mathrm{AA}$, and KCN (Fig. 5). Levels increased for $24 \mathrm{~h}$ after treatment (Fig. 5) but returned to the basal level by $48 \mathrm{~h}$ (data not shown).

\section{Chemically induced resistance can take place in nprl and sai 1 mutants.}

Arabidopsis plants require a functional copy of the NPR1 gene if they are to exhibit SA-induced resistance to bacterial or fungal pathogens. We carried out experiments to ascertain whether the NPRI gene was required for SA- or AA-induced resistance to the TVCV. Two allelic mutants were used: the npr1-1 mutant in the ecotype Columbia background (Cao et al. 1994) and the sail mutant line, which has an ecotype Nössen background (Shah et al. 1997). Leaves were detached from 4to 5-week-old plants and floated on water or chemical solutions for 2 days prior to inoculation with TVCV. RNA was then harvested from each sample at 5 days postinoculation. Figure 6 illustrates results obtained using wild-type Nössen and sail mutant plants. It can be seen that, in wild-type Nössen plants, SA and AA are effective in inducing resistance to virus, as seen by a reduction in viral RNA accumulation. This result is similar to the experiments carried out with wild-type Columbia plants (Figs. 1 and 2). When sail mutant plants were challenged with TVCV following treatment with SA or AA, they

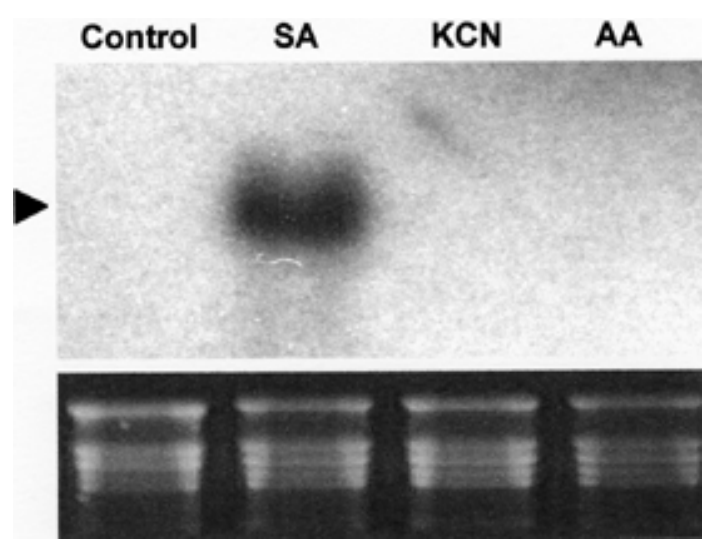

Fig. 4. Chemical induction of $P R-1$ gene expression in Arabidopsis leaf tissue. Arabidopsis leaves were floated on water (Control), $0.5 \mathrm{mM}$ salicylic acid (SA), $50 \mu \mathrm{M}$ potassium cyanide $(\mathrm{KCN})$, or $50 \mu \mathrm{M}$ antimycin A (AA). After 2 days, total RNA was extracted from the leaf tissue. To assess the steady-state level of $P R-1$ transcripts in each set of leaves, equal amounts $(10 \mu \mathrm{g})$ of RNA from each sample were analyzed by northern blotting using a ${ }^{32} \mathrm{P}$-labeled Arabidopsis $P R-1 \mathrm{cDNA}$ as the hybridization probe. The position of $P R-1$ is indicated by an arrow. The ethidium bromide-staining pattern for the same gel is shown in the bottom row to demonstrate equal loading of RNA. 
appeared to be as resistant to the virus as the wild type (Fig. 6). Experiments using nprl-1 mutant plants and wild-type Columbia plants in parallel yielded identical results (data not shown). Thus, SA- and AA-induced resistance to TVCV does not require NPR1. These experiments were carried out twice for each of the allelic mutants. Taken together with the results shown in Figures 1 and 3, the data confirms that, in Arabidopsis as in tobacco, induction of resistance to viruses is dependent on a distinct branch of the defensive signal transduction pathway that is separate from that required for PR-1 induction.

\section{The effect of mutations in NPRI}

\section{on the induction of Aox $1 a$ gene expression.}

Analysis of the promoter regions of inducible Aox genes revealed some similarities with the promoters for PR protein genes (Rhoads \& McIntosh 1993). We investigated whether the induction of Aox gene expression is dependant upon NPR1 activity. RT-PCR analysis was used to assess steady-state accumulation of Aox $1 a$ transcripts in leaf tissue of wild-type Arabidopsis (ecotype Columbia) or nprl-1 mutant plants after treatment with AA or SA (Fig. 7). We observed induction of Aox $1 a$ transcript in both wild-type and nprl-1 mutant plants treated with SA or AA. These results, obtained in two independent experiments (data not shown), show that SA-induced Aox gene expression is independent of NPR1 and are consistent with the possibility that AOX might be connected with SA-induced virus resistance.

\section{DISCUSSION}

We have shown that in two ecotypes of Arabidopsis, as in tobacco, nonlethal concentrations of cyanide and AA can induce resistance to a virus without triggering $P R-1$ gene expression. Furthermore, induction of virus resistance did not require the NPRl gene, which regulates SA-induced resistance to bacteria and fungi (Desprès et al. 2000; Zhou et al. 2000). These

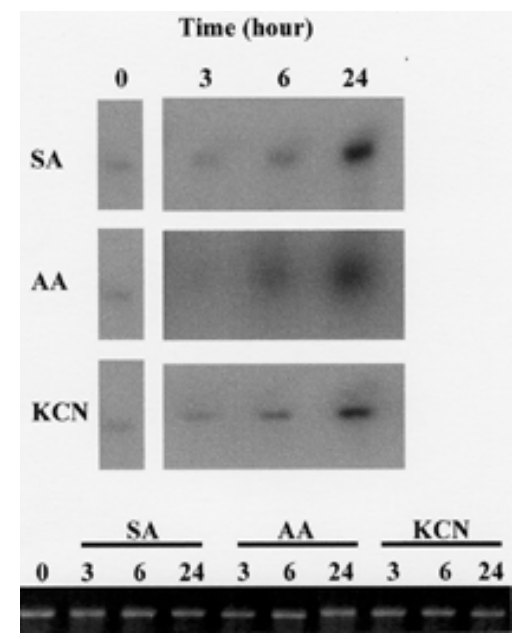

Fig. 5. Southern hybridization analysis of reverse-transcription polymerase chain reaction (RT-PCR)-amplified Aox $1 a$ cDNA fragments from total RNA extracted from Arabidopsis. Four-week-old plants were sprayed with $1 \mathrm{mM}$ salicylic acid (SA), $50 \mu \mathrm{M}$ potassium cyanide (KCN), or $50 \mu \mathrm{M}$ antimycin A (AA). Whole plants (three for each treatment) were collected for RNA extraction after the indicated time period. A total of $5 \mu \mathrm{g}$ of RNA was used as the template for the first- strand cDNA synthesis followed by 25 cycles of polymerase chain reaction. Aliquots ( $5 \mu \mathrm{l}$ of each) were run on an agarose gel and transferred to nitrocellulose membrane and probed with a ${ }^{32} \mathrm{P}-1$ abeled Aox $1 a$ fragment generated by random priming. An ethidium bromide-stained gel of $\beta$-tubulin DNA fragment amplified by RT-PCR from each RNA sample is shown in the bottom row. results confirm that induced resistance to plant viruses is dependent on a separate branch of the defensive signal transduction pathway from that needed for resistance to cellular pathogens. Importantly, these results also show that this branch is not unique to tobacco.

TVCV and TCV belong to different virus families, and they are both sensitive to SA-dependent resistance mechanisms. TCV infection of the Arabidopsis ecotype Dijon (Di-17) results in the development of a HR controlled by the dominant resistance gene, HRT (Dempsey et al. 1993, 1997). This resistance response is dependent upon SA but does not require a functional copy of NPRl (Kachroo et al. 2000). Kachroo and associates did not investigate whether resistance to TCV could be chemically induced. Nevertheless, it is reasonable to conclude that the resistance gene-mediated response to TCV exhibited by Di-17 (Kachroo et al. 2000) and the resistance to TVCV induced by chemical treatment of plants belonging to the susceptible Columbia and Nössen ecotypes as found in this study both require activation of the same virus-specific branch of the defensive signal transduction pathway.

Our analysis of viral protein and nucleic acid levels in SA-, AA-, and cyanide-treated Arabidopsis tissues showed that these chemicals inhibited the accumulation of the virus in the inoculated tissue. This suggests that induced resistance to this tobamovirus was due to either a decreased replication or cellto-cell movement, or both, of the virus. Thus, it appears that the SA-, AA-, and cyanide-induced resistance to TVCV in Arabidopsis has a similar mechanism (or mechanisms) to that induced in tobacco by the same chemicals against TMV, a closely related virus (Chivasa and Carr 1998; Chivasa et al. 1997).

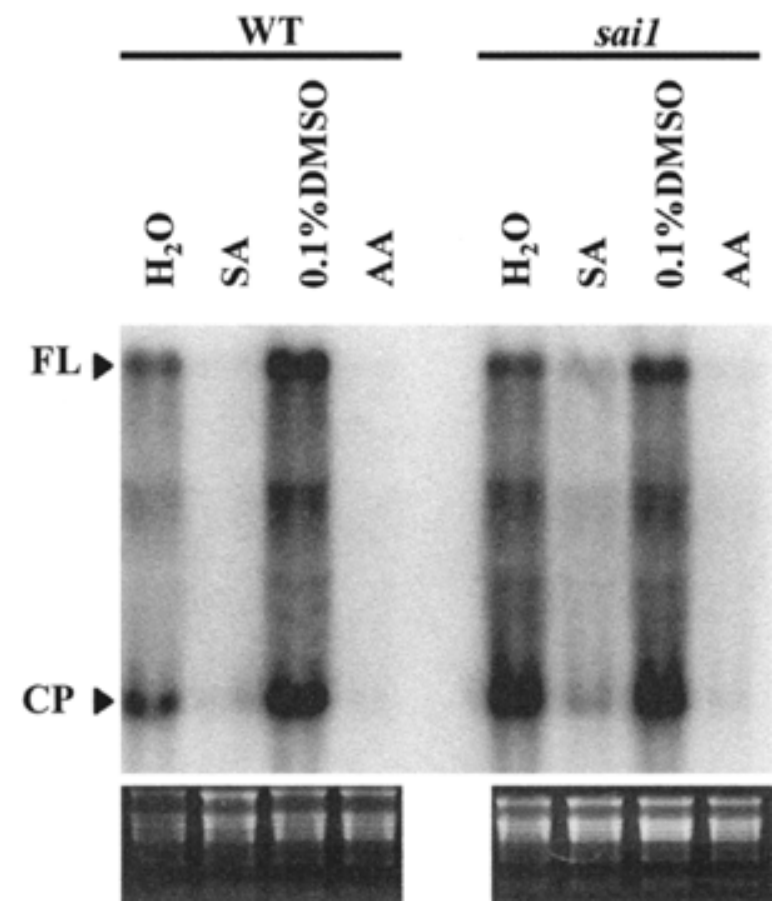

Fig. 6. Accumulation of Turnip vein clearing virus (TVCV)-specific RNA in chemically treated wild-type and sail mutant Arabidopsis leaf tissue. Detached leaves (10 per sample) were floated for 2 days on water (Control), $0.5 \mathrm{mM}$ salicylic acid (SA), 0.1\% dimethylsulfoxide (DMSO), or $50 \mu \mathrm{M}$ antimycin A (AA) prior to inoculation with TVCV $(10 \mu \mathrm{g} / \mathrm{ml})$. Leaves were returned to the replenished chemical solutions for 5 more days and harvested. RNA was extracted from each group of leaves. Equal amounts $(10 \mu \mathrm{g})$ of RNA from each sample were analyzed by northern blotting using a ${ }^{32} \mathrm{P}$-labeled Tobacco mosaic virus (TMV) coat protein cDNA as the hybridization probe. The ethidium bromide-staining pattern for the same gel is shown in the bottom row to demonstrate equal loading of RNA. 
Several recent studies have shown that either Aox gene expression or the capacity for AOX activity, or both, is increased in tobacco and Arabidopsis plants undergoing the HR (Chivasa et al. 1997; Lacomme and Roby 1999; Lennon et al. 1997; Simons et al. 1999) or after treatment of plants, organs, or tissues with SA or the synthetic resistance-inducing chemical, 2,6-dichloroisonicotinic acid (Chivasa and Carr 1998; Chivasa et al. 1999; Xie and Chen 1999). Further lines of evidence suggest that AOX may play a role in the induction of resistance to viruses (Chivasa and Carr 1998; Chivasa et al. 1997; Ji and Ding 2001; Naylor et al. 1998) but not in the induction by SA of PR protein gene expression or in the induction of resistance to fungal (Chivasa et al. 1997) or bacterial (Chivasa et al. 1997; Simons et al. 1999) pathogens.

Our results show that, as in tobacco, an increase in Aox gene expression correlates with the induction of resistance to viruses by SA, AA, and cyanide. We also investigated whether or not the NPRl gene is required for Aox gene induction by SA. This was considered possible because the promoter regions of several Aox genes in various plant species have some sequences in common with $P R$ gene promoters (Rhoads and McIntosh 1993). However, it appears that Aox la gene expression is not NPR1 dependent. If it had been, this experiment would have excluded the possibility that Aox gene expression is required for SA-induced resistance to viruses. As it stands, the result of this experiment is consistent with the possibility that AOX is part of the signaling pathway leading to the induction of resistance to viruses.

However, this potential connection between AOX and resistance to viruses remains based solely on pharmacological or correlative evidence and must, therefore, be treated with caution. For example, AOX may not be the authentic target of SHAM, since this chemical can also affect the activity of lipoxygenases (Preisig and Kuć 1987), as well as certain peroxidases (Møller et al. 1988). In fact, in our recent experiments, we found that SHAM was not reliable as an effective antagonist of SA-induced resistance to viruses (data not shown). This is in stark contrast to our results with tobacco, in which SHAM proved to be a reliable antagonist of SA-induced resistance to TMV (Chivasa and Carr 1998; Chivasa et al. 1997) as well as CMV and PVX (Naylor et al. 1998). Currently, efforts are underway to silence or reduce the expression of Aox genes and to assess the effect of this on SAinduced resistance to viruses.
In summary, this work has confirmed the existence of the virus-specific branch of the defensive signal transduction pathway and shown that it occurs in Arabidopsis. Finding the pathway in Arabidopsis has a further significance, given the utility of this plant for genetic studies (Kunkel 1996). Specifically, it will now be possible to devise mutant screens to identify those genes that regulate the induction by SA of resistance to viruses.

\section{MATERIALS AND METHODS}

Plants, virus, and chemical treatments.

Arabidopsis thaliana (L.) Heynh. plants (Columbia and Nössen ecotypes and nprl-1 and sail mutant plant lines) were grown in a Fitotron cabinet (Sanyo Ltd., Loughborough, U.K.) at $20^{\circ} \mathrm{C}$ with a 10 -h photoperiod.

Stock solutions of SA, SHAM (Sigma Chemical Co., Dorset, U.K.), and KCN (Fisher, Loughborough, U.K.) were freshly prepared in deionized water for each experiment. Solutions of SA or SA plus SHAM were adjusted to $\mathrm{pH} 6.5$ using potassium hydroxide. Solutions of $\mathrm{KCN}(50 \mu \mathrm{M})$ were not adjusted with acids or bases. AA (Sigma Chemical Co.) was dissolved in DMSO (Sigma Chemical Co.) to make $50 \mathrm{mM}$ stock. A 50- $\mu \mathrm{M}$ working solution was prepared after dilution in deionized water. Control treatments contained an equivalent volume of DMSO. For leaf floatation experiments, leaves were detached from 4- to 5-week-old plants and floated on water or chemical solutions for 2 days. Leaves were removed from solutions and inoculated with $10 \mu \mathrm{g}$ of purified TVCV per ml (Lartey et al. 1993) with Carborundum as an abrasive, applying the inoculum over the entirety of each leaf's adaxial surface with a cotton swab. Leaves were replaced in their original solutions and incubated for an additional 3 to 5 days before harvesting. For Aox la transcript analysis, 4-week-old Arabidopsis were sprayed with $1 \mathrm{mM} \mathrm{SA}, 50 \mu \mathrm{M} \mathrm{KCN}$, or $50 \mu \mathrm{M} \mathrm{AA}$, and whole plants were collected after the indicated time period.

\section{Protein analysis.}

For the detection of viral $\mathrm{CP}$, soluble proteins were extracted from plant tissue (typically 10 leaves per treatment) by homogenization, separated by SDS-PAGE, and electroblotted to nitrocellulose, using previously described methods (Carr et al. 1987). The blots were probed with a polyclonal rabbit antiserum raised against TMV CP. Binding of the primary antibodies was detected using a goat anti-rabbit immunoglobulin $\mathrm{G}$

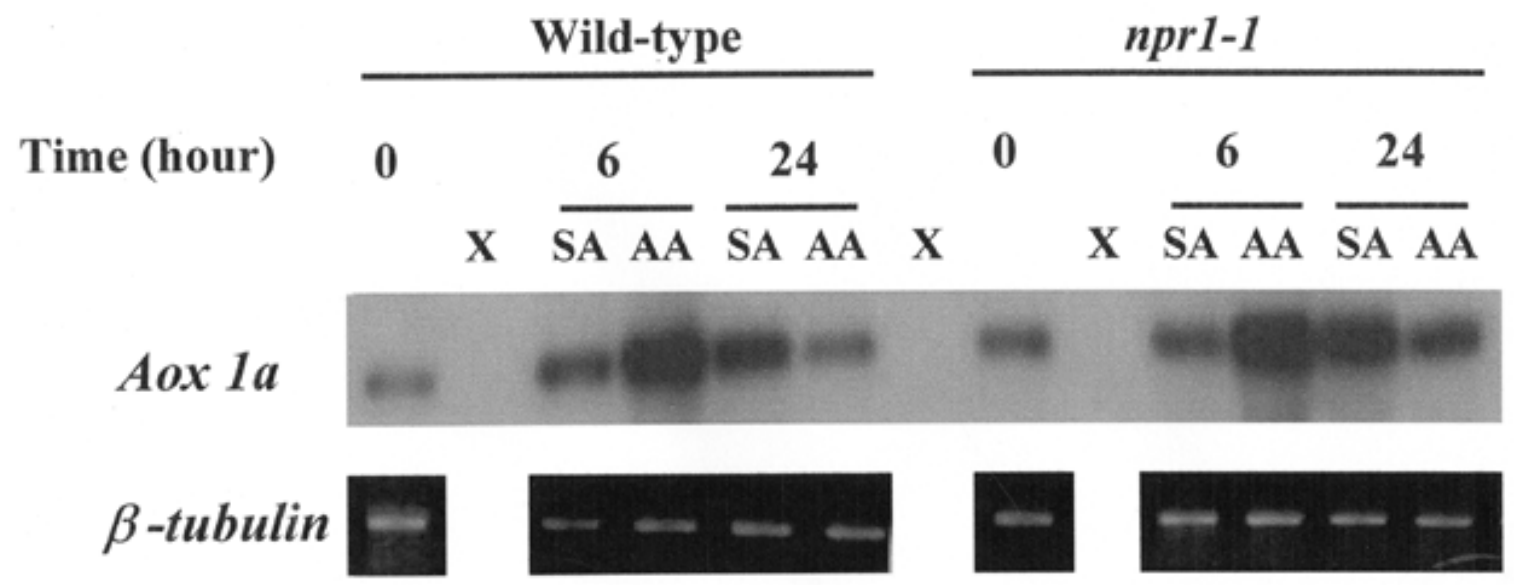

Fig. 7. Southern hybridization analysis of reverse-transcription polymerase chain reaction (RT-PCR)-amplified Aox $1 a$ cDNA fragments from total RNA extracted from wild type and $n p r l-1$. Four-week-old plants (three per treatment) were sprayed with $1 \mathrm{mM}$ salicylic acid (SA) or $50 \mu \mathrm{M}$ antimycin A (AA). Whole plants (three for each treatment) were collected for RNA extraction after the indicated time period. A total of $5 \mu \mathrm{g}$ of RNA was used as the template for the first-strand cDNA synthesis followed by 25 cycles of PCR. $5 \mu$ of each aliquots were run on an agarose gel and transferred to nitrocellulose membrane and probed with a ${ }^{32} \mathrm{P}-$ labeled Aox $1 a$ fragment generated by random priming. An ethidium bromide-stained gel of $\beta$-tubulin DNA fragment amplified by RT-PCR from each RNA sample is shown in the bottom row. 
horseradish peroxidase conjugate (Sigma Chemical Co.) using an enhanced chemiluminescence kit (Renaissance; NEN Life Science Products, Boston, MA, U.S.A.) and exposure to X-ray film.

To evaluate the effect of KCN or AA treatment on Arabidopsis protein synthesis, whole detached leaves (10 per treatment) that had been floated on water or on $50 \mu \mathrm{M} \mathrm{KCN}$ or $50 \mu \mathrm{M}$ AA for 3 days were incubated individually on 10- $\mu$ d drops of water containing L- $\left[{ }^{35} \mathrm{~S}\right]$ methionine (Amersham Life Science, Buckinghamshire, U.K.) at a concentration of $2.86 \mu \mathrm{Ci}$ per ml. After $4 \mathrm{~h}$, soluble proteins were extracted and analyzed by SDSPAGE and autoradiography (Chivasa and Carr 1998). Incorporation of the radiolabel into protein was quantified by measuring the amount of radioactivity present in the trichloroacetic acid-insoluble fraction using a liquid scintillation spectrometer (Tri-Carb Model 2000; United Technologies, Chicago, IL, U.S.A.).

\section{Extraction and analysis of RNA.}

Total RNA was extracted based on the method of Chomczynski and Sacchi (1987) with the incorporation of additional steps of phenol: chloroform extraction and lithium chloride precipitation after the isopropanol precipitation step. Total RNA $(10 \mu \mathrm{g})$ was separated on an agarose gel and blotted to nitrocellulose according to Sambrook and associates (1989). TVCV-specific RNA was detected using ${ }^{32} \mathrm{P}$-labeled cDNA fragment encoding the TMV-CP (Carr and Zaitlin 1991), which cross-hybridizes strongly to the $\mathrm{CP}$ gene sequence of TVCV. For detection of $P R-1$ gene expression, a ${ }^{32} \mathrm{P}$-labeled cDNA fragment (Metzler et al. 1991) was used as the hybridization probe.

For RT-PCR detection of Aox $1 a$ and $\beta$-tubulin (internal control) transcripts, sequences of gene-specific primers were the same as those used by Saisho and associates (1997) and Kang and Singh (2000), respectively. cDNA synthesis was carried out using Avian myoblastosis virus (AMV) reverse transcriptase (Promega, Madison, WI, U.S.A.) according to the manufacturer's instructions. PCR amplification of reverse transcriptase reactions was performed with $1 \mu \mathrm{l}$ of the cDNA reaction as the template using BIOTAQ polymerase (Bioline, London, U.K.) according to manufacturer's instructions. Reaction conditions were $5 \mathrm{~min}$ at $94^{\circ} \mathrm{C}$ followed by 25 cycles of $30 \mathrm{~s}$ at $94^{\circ} \mathrm{C}, 30 \mathrm{~s}$ at $60^{\circ} \mathrm{C}$, and $2 \mathrm{~min}$ at $72^{\circ} \mathrm{C}$. Aliquots $(5 \mu \mathrm{l} \mathrm{each})$ were run on an agarose gel and transferred to nitrocellulose membrane (Schleicher \& Schuell, Dassell, Germany) and probed with a ${ }^{32} \mathrm{P}$-labeled Aox $1 a$ fragment generated by random priming (Feinberg and Vogelstein 1983) using Prime-It II random prime labeling kit (Stratagene, La Jolla, CA, U.S.A.). Blots were visualized by autoradiography using Kodak Biomax film (Kodak, Rochester, NY, U.S.A.). For the internal control, ethidium bromide-stained $\beta$-tubulin DNA bands were visualized by UV transillumination and photographed, using a digital camera attached to a thermal printer.

\section{ACKNOWLEDGMENTS}

We thank S. Santa Cruz (Horticulture Research International (HRI), East Malling) for Turnip vein clearing virus, M. Wilson (HRI, Wellesbourne) for anti-Tobacco mosaic virus, and D. Klessig (Boyce Thompson Institute, Ithaca, NY, U.S.A.) for the $P R-1$ clone, npr1, and sail mutant lines, and for sharing data prior to publication. We also thank M. Handford and A. M. Murphy for their advice and suggestions. The work was funded, in part, by grants to J. P. Carr from the Biotechnological and Biological Research Council (BBSRC), Leverhulme Trust, and the Royal Society. R. A. J. Carson was supported by a BBSRC studentship, and C. E. Wong was supported by an Overseas Research Trust studentship, Cambridge Commonwealth Trust studentship, and a studentship from Corpus Christi College, Cambridge.

\section{LITERATURE CITED}

Affourtit, C., Krab, K., and Moore, A. L. 2001. Control of plant mitochondrial respiration. Biochim. Biophys. Acta-Bioenergetics 1504:5869.

Baker, B., Zambryski, P., Staskawicz, B., and Dinesh-Kumar, S. P. 1997. Signaling in plant-microbe interactions. Science 276:726-733.

Bowles, D. J. 1990. Defense-related proteins in higher plants. Annu. Rev. Biochem. 59:873-907.

Bradford, M. M. 1976. A rapid and sensitive method for the quantitation of microgram quantities of protein utilizing the principle of proteindye binding. Anal. Biochem. 72:248-254.

Carr, J. P., and Zaitlin, M. 1991. Resistance in transgenic plants expressing a nonstructural gene sequence of tobacco mosaic virus is a consequence of markedly reduced virus replication. Mol. Plant-Microbe Interact. 4:579-585.

Carr, J. P., Dixon, D. C., Nikolau, B. J., Voelkerding, K. V., and Klessig, D. F. 1987. Synthesis and localization of pathogenesis-related proteins in tobacco. Mol. Cell. Biol. 7:1580-1583.

Cao, H., Bowling, S. A., Gordon, S. A., and Dong, X. 1994. Characterization of an Arabidopsis mutant that is nonresponsive to inducers of systemic acquired resistance. Plant Cell 6:1583-1592.

Cao, H., Glazebrook, J., Clarke, J. D., Volko, S., and Dong, X. N. 1997. The Arabidopsis NPR1 gene that controls systemic acquired resistance encodes a novel protein containing ankyrin repeats. Cell 88:57-63.

Chivasa, S., and Carr, J. P. 1998. Cyanide restores $N$ gene-mediated resistance to tobacco mosaic virus in transgenic tobacco expressing salicylic acid hydroxylase. Plant Cell 10:1489-1498.

Chivasa, S., Murphy, A. M., Naylor, M., and Carr, J. P. 1997. Salicylic acid interferes with tobacco mosaic virus replication via a novel salicylhydroxamic acid-sensitive mechanism. Plant Cell 9:547-557.

Chivasa, S., Berry, J. O., apRees, T., and Carr, J. P. 1999. Changes in gene expression during development and thermogenesis in Arum. Aust. J. Plant Physiol. 26:391-399.

Chomczynski, P., and Sacchi, N. 1987. Single step method of RNA isolation by acid guanidium thiocyanate-phenol-chloroform extraction. Anal. Biochem. 162:156-159.

Cole, A. B., Király, L., Ross, K., and Schoelz, J. E. 2001. Uncoupling resistance from cell death in the hypersensitive response of Nicotiana species to Cauliflower mosaic virus infection. Mol. Plant-Microbe Interact. 14:31-41.

Cutt, J. R., Harpster, M. H., Dixon, D. C., Carr, J. P., Dunsmuir, P., and Klessig, D. F. 1989. Disease response to Tobacco mosaic virus in transgenic tobacco plants that constitutively express the pathogenesisrelated PR1b gene. Virology 173:89-97.

Day, D. A., Whelan, J., Millar, A. H., Siedow, J. N., and Wiskich, J. T. 1995. Regulation of the alternative oxidase in plants and fungi. Aust. J. Plant Physiol. 22:497-509.

Dempsey, D. A., Wobbe, K. K., and Klessig, D. F. 1993. Resistance and susceptible responses of Arabidopsis thaliana to turnip crinkle virus. Phytopathology 83:1021-1029.

Dempsey, D. A., Pathirana, M. S., Wobbe, K. K., and Klessig, D. F. 1997. Identification of an Arabidopsis locus required for resistance to turnip crinkle virus. Plant J. 11:301-311.

Dempsey, D. A., Shah, J., and Klessig, D. F. 1999. Salicylic acid and disease resistance in plants. Crit. Rev. Plant Sci. 18:547-575.

Després, C., DeLong, C., Glaze, S., Liu, E., and Frobert, P. R. 2000. The Arabidopsis NPR1/NIM1 protein enhances the DNA binding activity of a subgroup of the TGA family of bZIP transcription factors. Plant Cell 12:279-290

Feinberg, A. P., and Volgelstein, B. 1983. A technique for radiolabeling DNA restriction endonuclease fragments to high specific activity. Anal. Biochem. 132:6-13.

Genoud, T., and Métraux, J. P. 1999. Crosstalk in plant cell signaling: Structure and function of the genetic network. Trends Plant Sci. 4:503507.

Hammerschmidt, R. 1999. Induced disease resistance: How do induced plants stop pathogens? Physiol. Mol. Plant Pathol. 55:77-84.

Heath, M. C. 2000. Hypersensitive response-related death. Plant Mol. Biol. 44:321-334.

Hooft van Huijsduijnen, R. A. M., Albas, S. W., De Rijk, R. H., and Bol, J. F. 1986. Induction by salicylic acid of pathogenesis-related proteins and resistance to alfalfa mosaic virus in various plant species. J. Gen. Virol. 67:2135-2143.

Ji, L.-H., and Ding, S. W. 2001. The suppressor of transgene RNA silencing encoded by Cucumber mosaic virus interferes with salicylic acidmediated virus resistance. Mol. Plant-Microbe Interact. 14:715-724.

Kachroo, P., Yoshioka, K., Shah, J., Dooner, H. K., and Klessig, D. F. 2000. Resistance to turnip crinkle virus in Arabidopsis is regulated by two host genes and is salicylic acid dependent but NPRl, ethylene, 
and jasmonate independent. Plant Cell 12:677-690.

Kang, H., and Singh, K. B. 2000. Characterization of salicylic-acid responsive Arabidopsis Dof domain proteins: Overexpression of OBP3 leads to a growth defect. Plant J. 21:329-339.

Kim, C. H., and Palukaitis, P. 1997. The plant defense response to $\mathrm{Cu}$ cumber mosaic virus in cowpea is elicited by the viral polymerase gene and affects virus accumulation in single cells. EMBO (Eur. Mol. Biol. Organ.) J. 13:4060-4068.

Kunkel, B. N. 1996. A useful weed put to work: Genetic analysis of disease resistance in Arabidopsis thaliana. Trends Genet. 12:63-69.

Lacomme, C., and Roby, D. 1999. Identification of new early markers of the hypersensitive response in Arabidopsis thaliana. FEBS (Fed. Eur. Biochem. Soc.) Lett. 459:149-153.

Lartey, R. T., Hartson, S. D., Pennington, R. E., Sherwood, J. L., and Melcher, U. 1993. Occurrence of a vein-clearing tobamovirus in turnip. Plant Dis. 77:21-24.

Lartey, R. T., Ghoshroy, S., and Citovsky, V. 1998. Identification of an Arabidopsis thaliana mutation (vsm 1 ) that restricts systemic movement of tobamoviruses. Mol. Plant-Microbe Interact. 11:706-709.

Lennon, A. M., Neuenschwander, U. H., Ribas-Carbo, M., Giles, L., Ryals, J. A., and Siedow, J. N. 1997. The effects of salicylic acid and tobacco mosaic virus infection on the alternative oxidase of tobacco. Plant Physiol. 115:783-791.

Linthorst, H. J. M., Meuwissen, R. L. J., Kaufman, S., and Bol, J. F. 1989. Constitutive expression of pathogenesis-related proteins PR1, GRP, and PR-S in tobacco has no effect on virus infection. Plant Cell 1:285-291.

Maxwell, D. P., Wang, Y., and McIntosh, L. 1999. The alternative oxidase lowers mitochondrial reactive oxygen production in plant cells. Proc. Natl. Acad. Sci. U.S.A. 96:8271-8276.

Metzler, M. C., Cutt, J. R., and Klessig, D. F. 1991. Isolation and characterization of a PR-1 like protein from Arabidopsis thaliana. Plant Physiol. 96:346-348.

Mittler, R., Shulaev, V., Seskar, M., and Lam, E. 1996. Inhibition of programmed cell death in tobacco plants during a pathogen-induced hypersensitive response at low oxygen pressure. Plant Cell 8:1991-2001.

Møller, I. A., Bérczi, A., van der Plas, L. H. W., and Lambers, H. 1988. Measurement of the activity and capacity of the alternative oxidase in intact plant tissues: Identification of problems and possible solutions. Physiol. Plant. 72:642-649.

Moller, S. G., and Chua, N. H. 1999. Interactions and intersections of plant signaling pathways. J. Mol. Biol. 293:219-234.

Murphy, A. M., Chivasa, S., Singh, D. P., and Carr, J. P. 1999. Salicylic acid-induced resistance to viruses and other pathogens: A parting of the ways? Trends Plant Sci. 4:155-160.

Murphy, A. M., Gilliland, A., Wong, C. E., West, J., Singh, D. P., and Carr, J. P. 2001. Signal transduction in resistance to plant viruses. Eur. J. Plant Pathol. 107:121-128.

Naylor, M., Murphy, A. M., Berry, J. O., and Carr, J. P. 1998. Salicylic acid can induce resistance to plant virus movement. Mol. PlantMicrobe Interact. 11:860-868.

Preisig, C. L., and Kuć, J. A. 1987. Inhibition by salicylhydroxamic acid,
BW755C, eicosatetraynoic acid, and disulfiram of hypersensitive resistance elicited by arachidonic-acid or poly-L-lysine in potato tuber. Plant Physiol. 84:891-894.

Rhoads, D. M., and McIntosh, L. 1993 The SA-inducible Aox gene aox 1 and genes encoding PR protein share regions of sequence similarity in their promoters. Plant Mol. Biol. 21:615-624.

Ryals, J., Weymann, K., Lawton, K., Friedrich, L., Ellis, D., Steiner, H. Y., Johnson, J., Delaney, T. P., Jesse, T., Vos, P., and Uknes, S. 1997. The Arabidopsis NIM1 protein shows homology to the mammalian transcription factor inhibitor IאB. Plant Cell 9:425-439.

Saisho, D., Nambara, E., Naito, S., Tsutsumi, N., Hirai, A., and Nakazono, M. 1997. Characterization of the gene family for alternative oxidase from Arabidopsis thaliana. Plant Mol. Biol. 35:585-596.

Sambrook, J., Fritsch, E. F., and Maniatis, T. 1989. Molecular Cloning: A Laboratory Manual, 2nd ed. Cold Spring Harbor Laboratory, Cold Spring Harbor, NY, U.S.A.

Shah, J., Tsui, F., and Klessig, D. F. 1997. Characterization of a salicylic acid-insensitive mutant (sai1) of Arabidopsis thaliana, identified in a selective screen utilizing the SA-inducible expression of the tms2 gene. Mol. Plant-Microbe Interact. 10:69-78.

Simons, B. H., Millenaar, F. F., Mulder, L., van Loon, L. C., and Lambers, H. 1999. Enhanced expression and activation of the alternative oxidase during infection of Arabidopsis with Pseudomonas syringae pv tomato. Plant Physiol. 120:529-538.

Staskawicz, B., Ausubel, F. M., Baker, B. J., Ellis, J. G., and Jones, J. D. G. 1995. Molecular genetics of plant disease resistance. Science 268:661-667

van Loon, L. C., and van Strien, E. A. 1999. The families of pathogenesis-related proteins, their activities, and comparative analysis of PR-1 type proteins. Physiol. Mol. Plant Pathol. 55:85-97.

Wagner, A. M., and Moore, A. L. 1997. Structure and function of the plant alternative oxidase: Its putative role in the oxygen defense mechanism. Biosci. Rep. 17:319-333.

White, R. F., Antoniw, J. F., Carr, J. P., and Woods, R. D. 1983. The effects of aspirin and polyacrylic acid on the multiplication and spread of TMV in different cultivars of tobacco with and without the $\mathrm{N}$-gene. Phytopathol. Z. 107:224-232.

Wright, K. M., Duncan, G. H., Pradel, K. S., Carr, F., Wood, S., Oparka K. J., and Santa Cruz, S. 2000. Analysis of the $N$ gene hypersensitive response induced by a fluorescently tagged tobacco mosaic virus. Plant Physiol. 123:1375-1385.

Xie, Z. X., and Chen, Z. X. 1999. Salicylic acid induces rapid inhibition of mitochondrial electron transport and oxidative phosphorylation in tobacco cells. Plant Physiol. 120:217-225.

Yu, I. C., Parker, J., and Bent, A. F. 1999. Gene-for-gene disease resistance without the hypersensitive response in Arabidopsis $d n d 1$ mutant. Proc. Natl. Acad. Sci. U.S.A. 95:7819-7824.

Zhou, J.-M., Trifa, Y., Silva, H., Pontier, D., Lam, E., Shah, J., and Klessig, D. F. 2000. NPR1 differentially interacts with members of the TGA/OBF family of transcription factors that bind an element of the $P R-1$ gene required for induction by salicylic acid. Mol. Plant-Microbe Interact. 13:191-202. 